\title{
Iron(III) complexation by Vanchrobactin, a siderophore of the bacterial fish pathogen Vibrio anguillarum ${ }^{1}$
}

\author{
Emilia Iglesias $*^{a}$, Isabel Brandariz ${ }^{a}$, Carlos Jiménez ${ }^{b}$ and Raquel G. Soengas ${ }^{b}$ \\ ${ }^{a}$ Departamento de Química Física e E. Q. I, Facultad de Ciencias, Universidad de La Coruña, \\ 15008-La Coruña, Spain.E-mail: emilia.iglesias@udc.es \\ ${ }^{b}$ Departamento de Química Fundamental, Facultad de Ciencias, Universidad de La Coruña, \\ 15008-La Coruña, Spain
}

Metallomics, 2011, 3, 521-528

Received 4th November 2010 , Accepted 16th March 2011

DOI: 10.1039/C0MT00071J (Paper)

\begin{abstract}
The bacterial fish pathogen Vibrio anguillarum serotype $\mathrm{O} 2$ strain RV22 produces the mono catecholate siderophore Vanchrobactin $(\mathrm{Vb})$ under conditions of iron deficiency. $\mathrm{Vb}$ contains two potential bidentate coordination sites: catecholate and salicylate groups. The iron(III) coordination properties of $\mathrm{Vb}$ is investigated in aqueous solutions using spectrophotometric and potentiometric methods. The stepwise equilibrium constants $(\log K)$ for successive addition of $\mathrm{Vb}$ dianion to a ferric ion are 19.9; 13.3, and 9.5, respectively, for an overall association constant of 42.7. Based on the previous results, we estimated the equilibrium concentration of free iron(III) under physiological conditions for $\mathrm{pH} 7.4$ solution containing $10^{-6} \mathrm{M}$ totaliron and $10^{-5} \mathrm{M}$ total $\mathrm{Vb}$ as $\mathrm{pFe}=20$ $\left(=-\log \left[\mathrm{Fe}^{3+}\right]\right)$. The $\mathrm{Vb}$ model compounds catechol (Cat) and 2,4-dihydroxy- $N$ - $(2-$ hydroxyethyl)benzamide (Dhb) have also been examined, and the obtained results show that the interaction of the whole system of $\mathrm{Vb}$ that contains the ferric-chelating groups of both Dhb and Cat, is synergically greater than the separate parts; i.e. $\mathrm{Vb}$ is the best chelating agent either in acid or basic media. In summary, bacteria employing Vb-mediated iron transport thus are able to compete effectively for iron with other microorganisms within which they live.
\end{abstract}

\footnotetext{
${ }^{1}$ Supplementary information description: Fig. S1 shows the proportional increase of absorbance with $\mathrm{Vb}$ concentration in aqueous basic medium. Fig. S2 reports the absorption spectra of catechol-ferric ion aqueous solutions as a function of $\mathrm{pH}$ (4.9-8.7). The absorption spectra of Dhb are shown in Fig. S3.
} 


\section{Introduction}

Iron has a crucial biochemical role in an enormous range of cell redox processes in plants, bacteria and higher organisms. Although iron is the fourth most abundant element on Earth, its bioavailability is limited severely due to the stability and low solubility of its oxides under aqueous aerobic conditions at biological $\mathrm{pH}$. Under iron-deficient conditions, almost all microorganisms excrete highly efficient and specific ferric ion chelators, termed siderophores. ${ }^{1-9}$ The role of these compounds is to scavenge iron from the environment and to make themineral, which is almost always essential, available to the microbial cell.

Since siderophores differ substantially in structure, no uniform procedure is available for their isolation; however, they are relatively low weight molecules with a common feature of forming sixcoordinate octahedral complexes with iron(III) of great thermodynamic stability, ${ }^{10-14}$ where the chelating site usually contain the oxygen atoms of hydroxamate, catecholate orsalicylate anions. Natural siderophores (like e.g. enterobactin or mycobactin) are three-armed podands that bind $\mathrm{Fe}^{3+}$ through deprotonated hydroxyl groups of catecholate moieties: the hard nucleophilic character of these groups bind strongly the hard electrophile $\mathrm{Fe}^{3+}$. Although many siderophores possess six binding sites, several microbial chelators bearing fewer chelatinggroups have been described. ${ }^{15-17}$ One of them is Chrysobactin $(\mathrm{Cb})$, a monocatecholatetype siderophore of molecular structure very similar to that of Vanchrobactin. Recently, a detailed physicochemical study of the binding properties of ferric ions by $\mathrm{Cb}$, including the kinetics of formation and dissociation of the complexes, has been reported by Albrecht-Gary et al. ${ }^{17}$
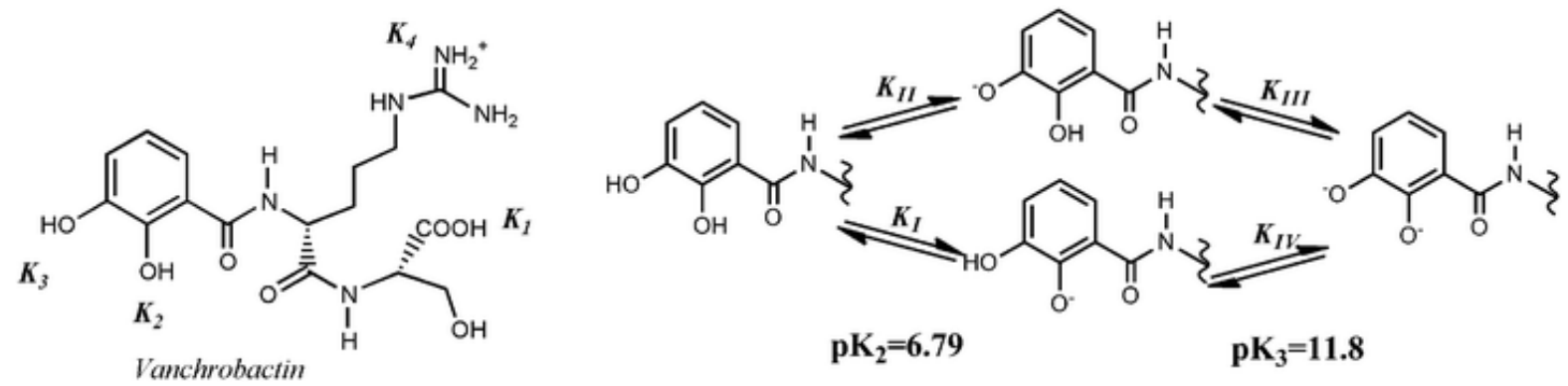

Scheme 1 Structure of fully protonated Vanchrobactin ( $\mathrm{Vb}$ ) and the acid dissociation equilibria of the catechol moiety, showing both macroscopic $\left(\mathrm{pK}_{2}\right.$, experimentally determined, and $\mathrm{pK}_{3}$, estimated value) and microscopic dissociation constants $\left(\mathrm{pK}_{i}\right.$ for $\left._{\mathrm{i}=\mathrm{I}, \mathrm{II}, \mathrm{III}, \mathrm{IV}}\right)$.

The present paper studies the $\mathrm{Fe}^{3+}$-complexation by natural Vanchrobactin ( $\left.\mathrm{Vb}\right)$, a new siderophore which was isolated from iron-deficient cultures of the bacteria fish pathogen Vibrio anguillarum serotype $\mathrm{O} 2$ strain RV22 and structurally characterized by total synthesis and chiral capillary electrophoresis analysis. ${ }^{18,19}$ The aim of the present work is to determine the association constants of ferric- $\mathrm{Vb}$ complexes in order to evaluate the affinity of $\mathrm{Vb}$ for iron(III). Since 
$\mathrm{Vb}$ contains both catechol and salicylic functions, which are potential chelating sites for ferric ions (Scheme 1), we studied also, for comparison purposes, the ferric complexation by 2,4-dihydroxy- $N$-(2hydroxyethyl)benzamide (Dhb) and catechol (Cat).

\section{Experimental}

Vanchrobactin can be extracted from iron-deficient cultures in CM9 medium of Vibrio anguillarun $;{ }^{19}$ nevertheless, the product used in this study was synthesized, starting from the commercially available 2,3-dihydroxybenzoic acid, following the procedure described by Soengas et $a l .{ }^{18}$ 2,4-Dihydroxy- $N$-(2-hydroxyethyl)benzamide and catechol were purchased from Aldrich of the maximum purity and used as received.

Stock solutions of $\mathrm{Fe}^{3+}$ were prepared by dissolving $\mathrm{FeCl}_{3} \cdot 6 \mathrm{H}_{2} \mathrm{O}(>98 \%)$ from Aldrich into standardized $\mathrm{HCl}$ to give a final solution which was typically $0.01 \mathrm{M}$ in iron(III) and $0.02 \mathrm{M}$ in acid.

Solutions of ferric- $\mathrm{Vb}$ complexes were prepared immediately before use by mixing appropriate volumes of the aqueous $\mathrm{Fe}^{3+}$ and ligand ( $\mathrm{Vb}$, Cat, or $\mathrm{Dhb}$ ) solutions in mild alkaline medium $(\mathrm{pH} \sim 10)$. The ratio of ligand to metal was always higher than three, i.e. $[\mathrm{Vb}]>3\left[\mathrm{Fe}^{3+}\right]$. The reaction mixture was stirred for a few minutes and divided into two portions for both spectrophotometric and potentiometric titrations. The solutions were deoxygenated by bubbling with purified nitrogen.

In order to avoid complications in the system due to internal redox reactions at low $\mathrm{pH}(\mathrm{pH}<3)$ that form ferrous semiquinones, which proceed irreversibly to byproducts, ${ }^{20,21}$ we have worked at $\mathrm{pHs}$ above 4. On the other hand, due to the alkaline hydrolysis of Vanchrobactin it was not possible to study the complexation process above $\mathrm{pH}=11$, approximately.

\subsection{Potentiometric titrations}

The titrations were performed in a jacketed cell maintained at $25.0( \pm 0.02){ }^{\circ} \mathrm{C}$ by means of a constanttemperature water circulating bath. A Crison microBu 2030 automatic burette furnished with a $2.5 \mathrm{~mL}$ syringe for dispensing the titrant was used. The burette was controlled with a computer that was used to read the emf values from a Crison micropH $2000 \mathrm{pH}$ meter connected to two electrodes: a glass electrode (Radiometer pHG211) and a reference electrode (Radiometer REF 201). The electrode response at constant ionic strength is given by $\varepsilon=\varepsilon^{o}+s \log \left[\mathrm{H}^{+}\right]$, where $\varepsilon$ is the emf, and the electrode parameters, the formal potential, $\varepsilon^{\circ}$, and the slope, $s$, are required by the program to determine the equilibrium constants. A separate experiment was carried out to obtain the electrode parameters: emf was measured in solutions of known hydrogen ion concentration, at the desired ionic strength, and $\varepsilon^{\mathrm{o}}$ was obtained from the linear regression data analysis. ${ }^{22}$ 
The potentiometric titration of ferric Vanchrobactin complexes $\left(\left[\mathrm{Fe}^{3+}\right]_{t}=0.085 \mathrm{mM},[\mathrm{Vb}]_{t}=0.39\right.$ $\mathrm{mM}$ ) were carried out by the addition of known volumes of standardized $\mathrm{HCl}$ (0.010 M, Merck p.a.) starting at $\mathrm{pH} \sim 10$. The necessary amount of $\mathrm{NaCl}$ (Merck, p.a.) to adjust the ionic strength, $I$, to the desired value was added to all solutions $(I=0.1 \mathrm{M})$. The solutions were continuously deoxygenated and homogenized by bubbling with purified nitrogen.

Equilibrium constants were calculated from the potentiometric titration data by means of the Hyperquad 2003 program. ${ }^{23}$ Iron hydrolysis was taken into account using the formation constant of the following species appearing in the literature, ${ }^{24} \log \beta\left(\mathrm{FeOH}^{2+}\right)=-2.563 ; \log \beta\left(\mathrm{Fe}(\mathrm{OH})_{2}\right)^{+}=-6.205 ; \log$ $\beta\left(\mathrm{Fe}(\mathrm{OH})_{4}\right)^{-}=-21.883 ; \log \beta\left(\mathrm{Fe}_{2}(\mathrm{OH})_{2}\right)^{4+}=-2.843$, and $\log \beta\left(\mathrm{Fe}_{3}(\mathrm{OH})_{4}\right)^{5+}=-6.054$.

\subsection{Spectrophotometric titrations}

In the spectrophotometric titrations the $\mathrm{pH}$ was adjusted in small increments by the addition of standardized $\mathrm{HCl}$ (0.010 M, Merck p.a.) or $\mathrm{NaOH}$ (0.010 M, Merck p.a.), and after stabilizing the $\mathrm{pH}$ (less than $15 \mathrm{~min}$ ), the UV-vis spectrum was recorded with a Kontron-Uvikon double beam spectrophotometer fitted with thermostated cell holders using quartz cells of $10.0 \mathrm{~mm}$ path. Data acquisition was performed with software supported by the manufacturer and converted to ASCII format for their analysis with common packet programs. Since equilibrium in some ferric complexes formation was slowly attained, each spectrum was recorded as a function of time in order to observe the final equilibration. Equilibrium constants determined from the spectrophotometric titrations were calculated by means of the Hyperquad program.

\section{Results and discussion}

Vanchrobactin is a dipeptide composed by serine and arginine amino acid residues linked to the 2,3dihydroxybenzoyl moiety. Two potential bidentate coordination sites of ferric ions are present in the $\mathrm{Vb}$ molecule: catecholate and salicylate groups. The $\mathrm{Vb}$ molecule contains several ionizable groups that facilitate its water solubility. The guanidine group of arginine unit remains protonated over an extremely wide $\mathrm{pH}$ range $\left(\mathrm{pK}_{4} \sim 13.6\right),{ }^{25}$ and because of that it is an excellent anion binding site; the $\mathrm{pK}_{1}$ of the serine residue must be around 3 , therefore, under the experimental conditions of the present work (i.e. $4<\mathrm{pH}<11$ ), the $\mathrm{N}$-atom of guanidine group remains protonated $\left(-\mathrm{NH}-\mathrm{C}\left(\mathrm{NH}_{2}{ }^{+}\right)-\mathrm{NH}_{2}\right)$, whereas the serine acid group is ionized $\left(-\mathrm{COO}^{-}\right)$, Scheme 1. The acidity constants of the catechol moiety have been detemined in this work.

On studying the stability of the $\mathrm{Vb}$ at different $\mathrm{pH}$ values, we have observed that in alkaline medium of $\mathrm{pH}>12$ (experimental conditions of $\left[\mathrm{OH}^{-}\right]=0.039 \mathrm{M}$ ) the characteristic absorption band of $\mathrm{Vb}\left(\lambda_{\max } 335 \mathrm{~nm}\right)$ disappears relatively fast ( $<20 \mathrm{~min}$ ) by describing clear isosbestic points, Fig. 1(a). By contrast, within the $\mathrm{pH}$ interval of 4 to 11 , this band is completely stable; nevertheless, 
the spectrum changes with the $\mathrm{pH}$ in both the absorption intensity and the position of the maximum wavelength absorption, Fig. 1(b). The isosbestic point drawn around $310 \mathrm{~nm}$ in the $\mathrm{pH}$ titration spectra is indicative of an acid-base equilibrium between two species.
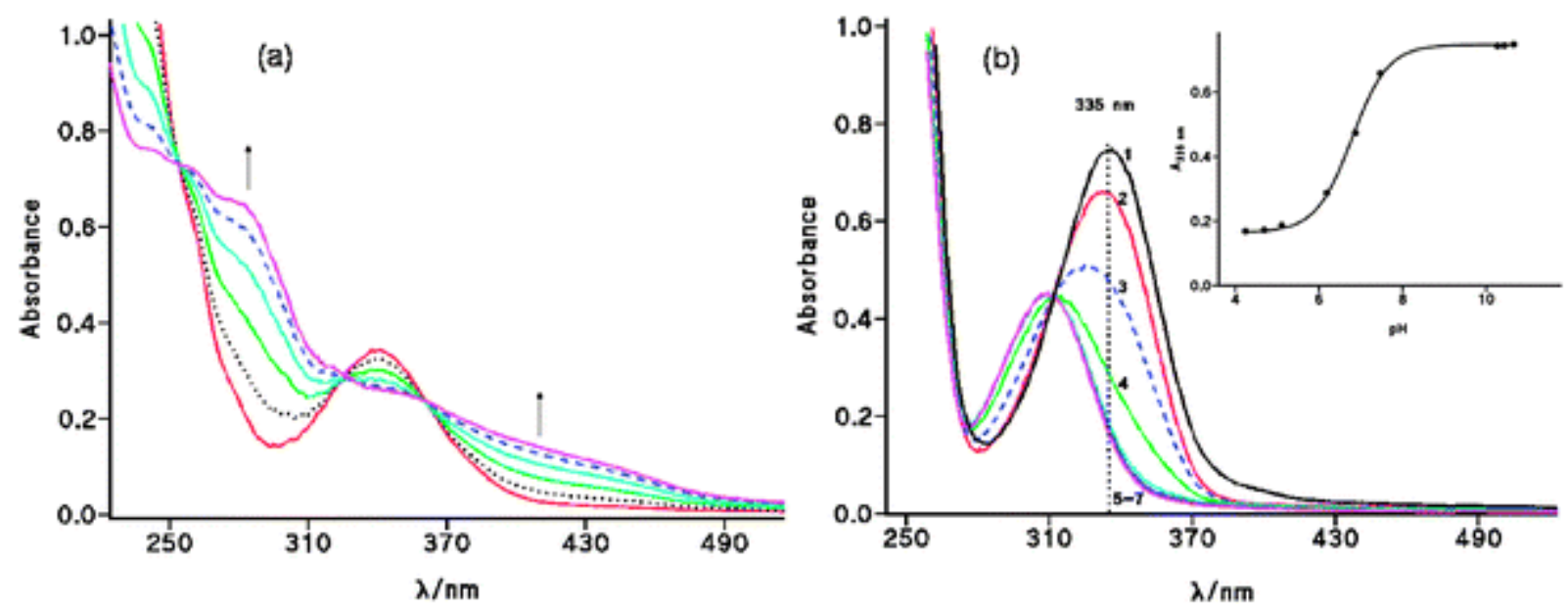

Fig. 1 (a) Repeat scans each 3 min showing the decomposition of $\mathrm{Vb}$ in alkaline medium, $\left[\mathrm{OH}^{-}\right]=0.039 \mathrm{M}$, $[\mathrm{Vb}]=0.15 \mathrm{mM}$; (b) UV-vis spectra of $\mathrm{Vb} 0.30 \mathrm{mM}$ registered as a function of $\mathrm{pH}$ : [1] $\mathrm{pH} 10.44$ (carbonate/ bicarbonate buffer 0.024 M), [2] pH 7.47, [3] pH 6.87, [4] pH 6.19 (hydrogen phosphate-dihydrogen phosphate, $0.050 \mathrm{M}$ ), [5] to [7] $\mathrm{pHs} 5.11,4.69$ and 4.24 (acetic acid-acetate, $0.085 \mathrm{M}$ ); the inset shows the spectrophotometric titrationcurve of $\mathrm{A}_{335 \mathrm{~nm}} v s . \mathrm{pH}$.

In aqueous buffered medium of $\mathrm{HCO}_{3}{ }^{-} / \mathrm{CO}_{3}{ }^{-2}$ of $\mathrm{pH} 10.45$ and $0.020 \mathrm{M}$, the variation of absorbance at $335 \mathrm{~nm}$ (the $\lambda_{\max }$ in basic medium) has been measured for different $\mathrm{Vb}$ concentrations (within the interval of $0.03-0.7 \mathrm{mM}$ ); the results show a perfectly linear plot (Fig. S1 $\dagger$ ) whose slope gives the molar $\mathrm{Vb}$ absorption as $\varepsilon=(2445 \pm 14) \mathrm{M}^{-1} \mathrm{~cm}^{-1}$. At this wavelength and constant $\mathrm{Vb}$ concentration of $0.30 \mathrm{mM}$, the plot of the absorbance readings (A), measured as a function of $\mathrm{pH}$, drawn typical spectroscopic titration curve, see inset of Fig. 1(b). The quantitative treatment of $\mathrm{A}_{335}$ $\mathrm{pH}$ data according to eqn (1), which can be easily derived ${ }^{26}$ by taking into account that $\mathrm{A}=\varepsilon_{a} \ell_{[}[\mathrm{VbH}]$ $+\varepsilon_{b}{ }^{\ell}\left[\mathrm{Vb}^{-}\right] ;[\mathrm{Vb}]_{\mathrm{o}}=[\mathrm{VbH}]+\left[\mathrm{Vb}^{-}\right]$and the first acid ionization macroscopic constant $\mathrm{K}_{2}$ of the catechol group, yielded a perfect fit of this equation to the experimental points when $\mathrm{pK}_{2}=6.79 \pm$ 0.02 and the input values of $\mathrm{A}_{a}=0.165$ and $\mathrm{A}_{b}=0.748$ corresponding to the absorbance readings of $\mathrm{Vb}$ solution for the most acidic and most basic $\mathrm{pH}$ values, respectively.

$$
A_{335}=\frac{A_{a} 10^{\mathrm{pK} K_{2}}+A_{b} 10^{\mathrm{pH}}}{10^{\mathrm{pK}}+10^{\mathrm{pH}}}
$$

The experimental value of $\mathrm{K}_{2}$ corresponds to the macroscopic dissociation constant, i.e. $\mathrm{K}_{2}=\mathrm{K}_{\mathrm{I}}+$ $\mathrm{K}_{\mathrm{II}}$ of Scheme 1. In order to separate the values of the microscopic constants, $\mathrm{K}_{\mathrm{I}}$ and $\mathrm{K}_{\mathrm{II}}$, we used the 
Hammett equation for phenols: $\mathrm{pK}=9.92-2.23 \Sigma \sigma$ and the Hammett $\sigma$-constants corresponding to ortho-position- $\sigma_{\mathrm{o}}(-\mathrm{OH})=0.04$ and $\sigma_{m}\left(-\mathrm{CONH}_{2}\right)=0.28$ - to estimate the $\mathrm{pK}_{\mathrm{II}}$ as $9.20 ;{ }^{27}$ then, from this estimate and the experimental $\mathrm{pK}_{2}$ one determines $\mathrm{pK}_{\mathrm{I}}=6.79$, i.e. the microscopic $\mathrm{pK}_{\mathrm{I}}$ equals the macroscopic $\mathrm{pK}_{2}$. The high difference in $\Delta \mathrm{pK}=\mathrm{pK}_{\mathrm{II}}-\mathrm{pK}_{\mathrm{I}}=2.41$, in comparison to that observed in e.g. pyrogallol $(\Delta \mathrm{pK}=0.50)$ or catechol, is due to both the electron-withdrawing effect of the amide moiety and the stabilization of the deprotonated $o$-hydroxyl through an intramolecular $\mathrm{H}$ bonding in a six-member ring with the amide hydrogen. In addition, this $\mathrm{pK}_{2}$-value is quite similar to that observed in Chrysobactin, ${ }^{17}$ whose molecular structure resembles that of $\mathrm{Vb}$, Scheme 2 . The high difference between $\mathrm{K}_{\mathrm{I}}$ and $\mathrm{K}_{\mathrm{II}}$ makes insignificant the tautomerization between both mono-anions of catechol moiety. The experimental determination of $\mathrm{pK}_{3}$ is not possible due to the $\mathrm{Vb}$ decomposition observed above $\mathrm{pH}>11$, approximately. However, proceeding in the same manner as for $\mathrm{pK}_{\mathrm{II}}$, it can be done an estimation of the second ionization constant of catechol moiety as $\mathrm{pK}_{3}=$ 11.80 (i.e. by taking into account that now the $o$-substituend is $-\mathrm{O}^{-}$for which $\sigma_{\mathrm{o}}\left(-\mathrm{O}^{-}\right)=-1.10$, which yields $\mathrm{pK}_{\mathrm{III}}=10.77$ and $\left.\mathrm{pK}_{\mathrm{IV}}=11.75\right)$.<smiles>Oc1ccccc1O</smiles>

Catechol, Cat<smiles>CN(C)C(=O)c1cccc(O)c1O</smiles>

$N, N$-dimethyl-2,3-dihydroxybenzamide $D M B$<smiles>O=C(NCCO)c1ccc(O)cc1O</smiles>

2,4-dihydroxy-(N-2-hydroxyethyl)benzamide Dhb<smiles>NCCCC[C@H](NC(=O)c1cccc(O)c1O)C(=O)NC(CO)CO</smiles>

Chrysobactin, $\mathrm{Cb}$

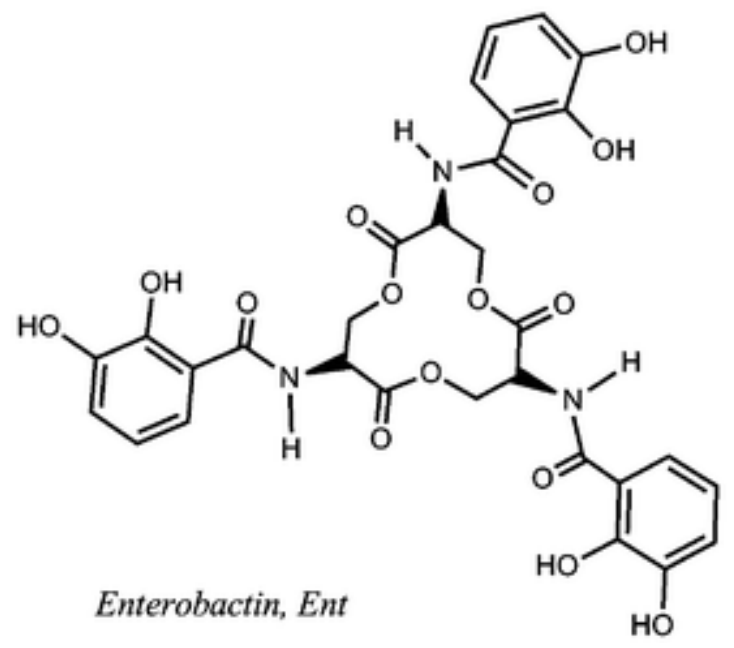

Scheme 2 Molecular structures of ferric ion-ligands used to compare the results of $\mathrm{Vb}$.

We studied the iron complexes of Vanchrobactin in the $\mathrm{pH}$ range of 4-11, because below $\mathrm{pH} 4$, the complexes are unstable and in alkaline medium the ligand hydrolyses. The $\mathrm{pH}$ dependence of the ferric Vanchrobactin visible spectrum is displayed in Fig. 2(a). Fig. 2(b) shows the spectrophotometric titration curves at different wavelengths; absorbance readings at $700 \mathrm{~nm}$ accounts mainly to the increase of $[\mathrm{Fe}(\mathrm{Vb})]^{+}$as the $\mathrm{pH}$ decreases, i.e. equilibrium (2); whereas the absorbance readings at 495 
$\mathrm{nm}$ (or $450 \mathrm{~nm}$ ) reflect the increase in $\left[\mathrm{Fe}(\mathrm{Vb})_{3}\right]^{3-}$ with the $\mathrm{pH}$, i.e. equilibrium (4); nevertheless, the absorbance readings at $545 \mathrm{~nm}$ that is an isosbestic point of di- and tri-ferric complex, decreases when the equilibrium (2) becomes important. Therefore, the spectrum reflects the presence of three sequential complexation reactions, (2) to (4). In this sense, the spectrum does not change above $\mathrm{pH}$ 7.45 , which indicates the full formation of hexa-coordinated $\left[\mathrm{Fe}(\mathrm{Vb})_{3}\right]^{3-}$ complex that gives a deep red solution with $\lambda_{\max } 495 \mathrm{~nm}\left(\varepsilon=3750 \mathrm{M}^{-1} \mathrm{~cm}^{-1}\right)$.

$$
\begin{gathered}
\mathrm{Fe}^{3+}+\mathrm{Vb}^{2-} \stackrel{K_{\mathrm{Nab}}}{\rightleftharpoons} \mathrm{Fe}(\mathrm{Vb})^{+} \\
\mathrm{Fe}(\mathrm{Vb})^{+}+\mathrm{Vb}^{2-} \stackrel{K_{\mathrm{Ma}_{2}}}{\rightleftharpoons}\left[\mathrm{Fe}(\mathrm{Vb})_{2}\right]^{-} \\
{\left[\mathrm{Fe}(\mathrm{Vb})_{2}\right]^{-}+\mathrm{Vb}^{2-} \stackrel{K_{\mathrm{Mn}_{3}}}{\rightleftharpoons}\left[\mathrm{Fe}(\mathrm{Vb})_{3}\right]^{3-}}
\end{gathered}
$$

As the $\mathrm{pH}$ is lowered from 7.45 to 5.07 , an isosbestic point appears at $545 \mathrm{~nm}$, consistent with a simple equilibrium between two metal complexes absorbing in the visible region. The observed spectrum results from the overlap of the absorption bands of $\left[\mathrm{Fe}(\mathrm{Vb})_{3}\right]^{3-}$ and $\left[\mathrm{Fe}(\mathrm{Vb})_{2}\right]^{-}$. The spectrum at $\mathrm{pH} 6.02$ corresponds essentially to that of the bis-complex, which has a band maximum at $560 \mathrm{~nm}\left(\varepsilon=2900 \mathrm{M}^{-1} \mathrm{~cm}^{-1}\right)$. Further lowering the $\mathrm{pH}$ from 5 to 3.99 , a new isosbestic point appears at $700 \mathrm{~nm}$ while the solution turns dark blue, with maximum absorption at $600 \mathrm{~nm}$; now reflecting the overlap of the spectra of $\left[\mathrm{Fe}(\mathrm{Vb})_{2}\right]^{-}$and $[\mathrm{FeVb}]^{+}$. The spectral data recorded in the $\mathrm{pH}$ range 4-10 were analysed using the Hyperquad program. Three absorbing species were determined, namely, $\left[\mathrm{Fe}(\mathrm{Vb})_{3}\right]^{3-},\left[\mathrm{Fe}(\mathrm{Vb})_{2}\right]^{-}$, and $[\mathrm{Fe}(\mathrm{Vb})]^{+}$, and their respective global stability constant were thus evaluated. The calculated electronic spectra of the ferric mono-, bis-, and tris $(\mathrm{Vb})$ complexes are given in Fig. 3.
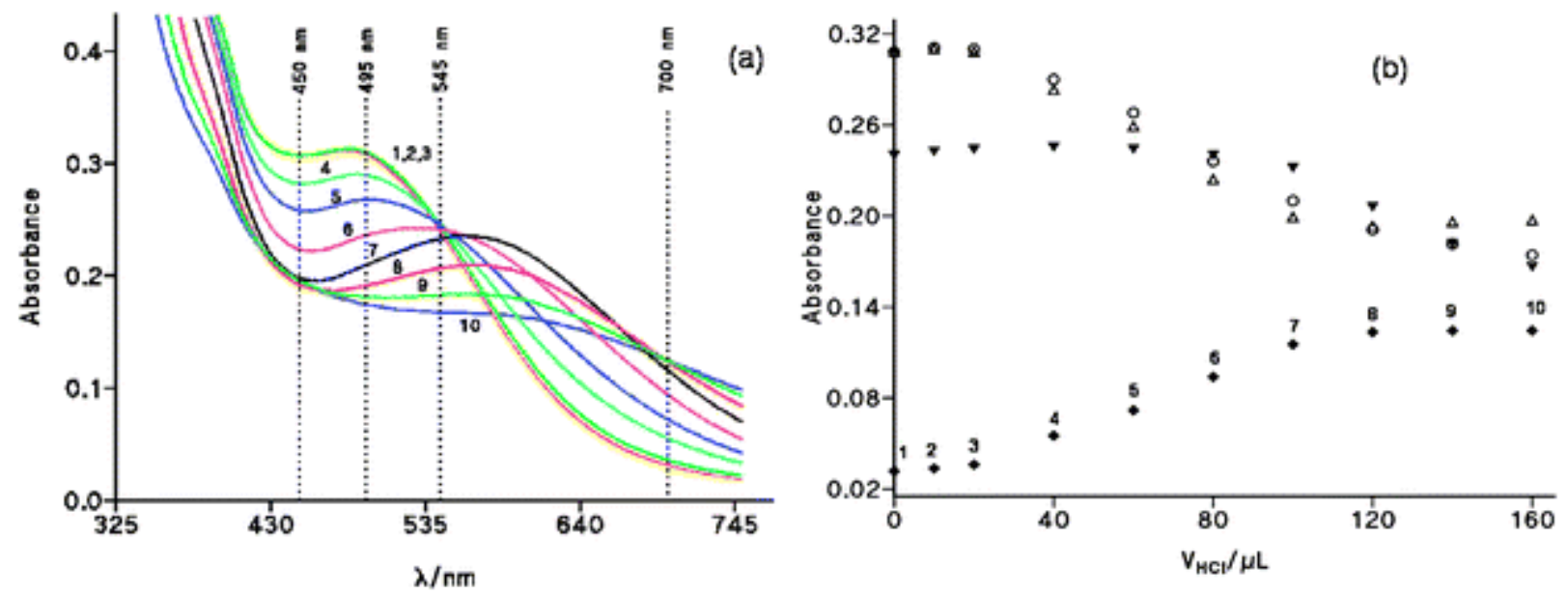

Fig. 2 (a) Visible spectra (corrected for dilution) of $4: 1 \mathrm{Vb}: \mathrm{Fe}^{3+}$ solution $\left([\mathrm{Vb}]=0.33 \mathrm{mM} ;\left[\mathrm{Fe}^{3+}\right]=82 \mu \mathrm{M}\right)$ as a function of pH: (1) 9.40; (2) 8.50; (3) 7.45; (4) 6.97; (5) 6.71; (6) 6.02; (7) 5.07; (8) 4.62; (9) 4.27; (10) 3.99; (b) spectrophotometric titration curves measured at different wavelengths: $(\diamond) 700 \mathrm{~nm}$; $(\boldsymbol{\nabla}) 545 \mathrm{~nm} ;(\Delta) 450$ 
nm, and (०) $495 \mathrm{~nm}$.
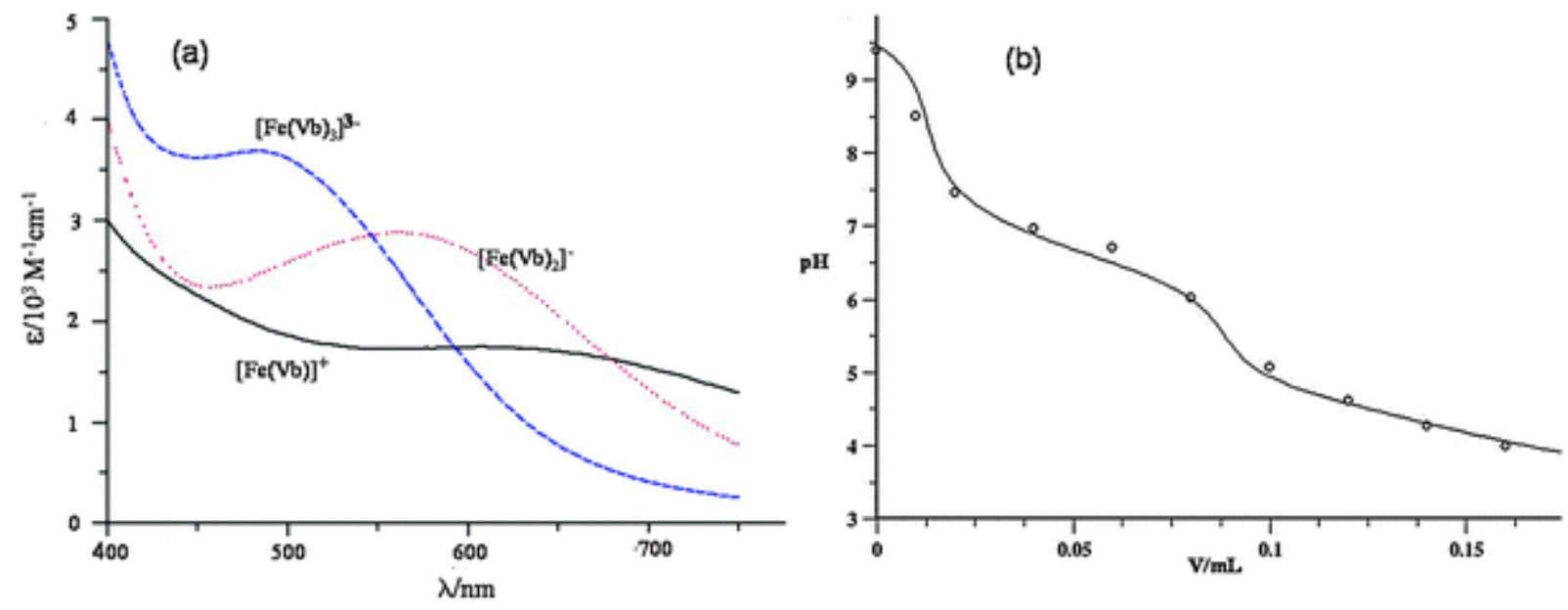

Fig. 3 (a) Calculated electronic spectra of ferric Vanchrobactin complexes and (b)potentiometric titration curve of ferric- $\mathrm{Vb}$ aqueous solution.

Potentiometric titration of ferric Vanchrobactin complexes in $\mathrm{NaOH}$ was titrated with $\mathrm{HCl}$. The resulting titration curve of Fig. 3 reflects both complexation and ligand deprotonation equilibria. The figure clearly indicates the stepwise formation of the ferric mono-, bis-, and tris $(\mathrm{Vb})$ complexes.

Both spectrophotometric and potentiometric titration data were fitted with Hyperquad to determine the complexation equilibrium constants. The deviations between the calculated constants obtained from both experimental methods are of the order of the experimental error and the average of the complexation constants obtained for the same process are listed in Table 1. Data are given for the equilibria stated in eqn (2) to (4), where $\mathrm{Vb}^{2-}$ represents the $\mathrm{Vb}$ molecule deprotonated at the carboxylic acid and at both catechol $\mathrm{OH}$ groups.

As $\mathrm{pH}$ was not low enough to find accurate $\log K_{\mathrm{ML}}$, we have assumed the same value obtained for catechol, 19.9, vide infra, to get the constants listed in Table 1. As it can be observed, the values for catechol and $\mathrm{Vb}$, obtained in this way, are quite similar, which is more than reasonable taking into account that it is the same metal and the complexations sites are the same: the catecholate moiety, is known to be one of the best iron chelating agents in nature. Although complexation constants are almost equal, $\mathrm{Vb}$ is a more effective ligand than catechol for removing iron from a solution, because the protons of the hydroxyl groups are considerably more acidic than those of catechol (6.79 and 11.8 compared to 9.3 and 13.3). A common way to illustrate the different ability of a ligand to sequester ferric ion, is to calculate the equilibrium concentration of free iron(III) in a solution of specified $\mathrm{pH}$, total iron and total ligand concentrations. ${ }^{7}$ The ligand is more effective when $\left[\mathrm{Fe}^{3+}\right]$ is smaller or $-\log \left[\mathrm{Fe}^{3+}\right]=\mathrm{pFe}$ is larger. Thus, in a solution containing $10^{-6} \mathrm{M}$ of total iron(III) and $10^{-5} \mathrm{M}$ total ligand at the biological $\mathrm{pH} 7.4$, the data in Table 1 gives $\mathrm{pFe}(\mathrm{Cat})=15$ and $\mathrm{pFe}(\mathrm{Vb})=20$, that is, the 
concentration of free iron(III) is 5 orders of magnitude smaller in a solution of $\mathrm{Vb}$ than in one ofcatechol, clearly indicating that $\mathrm{Vb}$ is a more powerful sequestering agent.

Table 1 Experimental and literature values of the successive acid ionization constants (pK) of free ligands $\left(\mathrm{LH}_{n}\right)$, Vanchrobactin $\left(\mathrm{Vb}, \mathrm{LH}_{4}\right) ; 2$,4-dihydroxy- $N$-(2-hydroxyethyl)-benzamide(Dhb, $\left.\mathrm{LH}_{2}\right)$; catechol $\left(\mathrm{Cat}, \mathrm{LH}_{2}\right) ; \mathrm{N}, \mathrm{N}$ dimethyl-2,3-dihydroxybenzamide (DMB, $\left.\mathrm{LH}_{2}\right)$; chrysobactin $\left(\mathrm{Cb}, \mathrm{LH}_{4}\right)$, and enterobactin (Ent, $\left.\mathrm{LH}_{6}\right)$, and stepwise stability constants of $\mathrm{Fe}^{+3}$ complexes with the deprotonated form of the ligand $\left(\log K_{\mathrm{ML} n}\right)$. The value of $\beta_{\mathrm{L} 3}$ refers to the global stability constant of ferric-ligand complex, i.e. $\mathrm{Fe}^{3+}+3 \mathrm{~L}^{n-} \rightleftarrows\left[\mathrm{FeL}_{3}\right]^{3(1-n)}$

\begin{tabular}{|c|c|c|c|c|c|c|c|c|}
\hline \multirow[b]{2}{*}{ Ligand $^{a}$} & \multicolumn{2}{|c|}{$\mathrm{LH}_{n} \stackrel{K_{n-3}}{\rightleftharpoons} \mathrm{LH}_{n-1}^{3-n}+\mathrm{H}^{+}$} & \multicolumn{6}{|c|}{$\mathrm{ML}_{n-1}^{3-m}+\mathrm{L}^{-m} \stackrel{\mathrm{K}_{\mathrm{Mn}_{n}}}{\rightleftharpoons}\left[\mathrm{ML}_{n}\right]^{3-m \cdot n}$} \\
\hline & $\mathbf{p K}_{1}$ & $\mathbf{p K}_{2}$ & $\mathrm{pK}_{3}$ & $\mathbf{p K}_{4}$ & $\log K_{\mathrm{ML}}$ & $\log K_{\mathrm{ML2}}$ & $\log K_{\mathrm{ML3}}$ & $\log \beta_{\mathrm{FeL3}}$ \\
\hline $\mathrm{Vb}^{b}$ & 3.2 & $6.79 \pm 0.02$ & 11.8 & 13.6 & 19.9 & $13.3 \pm 0.3$ & $9.5 \pm 0.3$ & 42.7 \\
\hline $\mathrm{Dhb}^{b}$ & $7.55 \pm 0.01$ & $9.75 \pm 0.01$ & - & - & $7.8 \pm 0.1$ & $7.1 \pm 0.1$ & $5.5 \pm 0.1$ & 20.4 \\
\hline $\mathrm{Cat}^{b}$ & $9.32 \pm 0.01$ & 13.05 & - & - & $19.9 \pm 0.4$ & $14.9 \pm 0.3$ & $9.8 \pm 0.3$ & 44.6 \\
\hline $\mathrm{Cat}^{c}$ & 9.30 & $\sim 13.3$ & - & - & 20.4 & 15.10 & 9.4 & 44.9 \\
\hline $\mathrm{DMB}^{d}$ & 8.42 & 12.1 & - & - & 17.7 & 13.96 & 8.51 & 40.24 \\
\hline $\mathrm{Cb}^{e}$ & 3.17 & 6.73 & 10.61 & 12.1 & $19.3^{f}$ & $12.6^{f}$ & $8.3^{f}$ & 40.2 \\
\hline $\mathrm{Ent}^{g}$ & 7.6 & 8.4 & 9.2 & - & 52 & - & - & $52^{h}$ \\
\hline
\end{tabular}

$a$ See Scheme 2 for ligand molecular structure. $b$ This work. $c$ Ref. 29. $d$ Ref. 7. $e$ Ref. 17. $f$ Estimated stability constants for the $\mathrm{Cb}$-ligand protonated on theamine group. $g$ The enterobactin molecule contains three catecholate groups, ref. 7. $h$ Hexacoordinated complex with one ligand.

Chrysobactin $(\mathrm{Cb})$ is a natural siderophore, recently studied in detail by Albrecht-Gary et al. ${ }^{17}$ of particular importance here to compare with $\mathrm{Vb}$ because their molecular structures are quite similar. The guanidine group of $\mathrm{Vb}$, with $\mathrm{pK} \sim 13.6$, is replaced by the amine group in $\mathrm{Cb}$; nevertheless, this simple change makes the $\mathrm{Cb}$ a more complicated system, because theamine group changes its protonation state during the titration, while guanidine remains protonated throughout all the $\mathrm{pH}$ range. Therefore, it is difficult the comparison of the complexation constants of $\mathrm{Vb}$ with those of $\mathrm{Cb}$. In this sense, it is necessary to consider three different values of the global stability constants for the formation of tris $(\mathrm{Cb})$ complexes at basic $\mathrm{pH}$, as is stated in the work of Albrecht-Gary and represent here in eqn (5) to (7), respectively, to the different successive protonation state of the amine group of the ligand, where $\mathrm{Cb}^{3-}$ represents the fully deprotoned chrysobactin molecule: 


$$
\begin{aligned}
& \mathrm{Fe}^{3+}+3 \mathrm{Cb}^{3-}+\mathrm{H}^{+} \stackrel{\beta_{\mathrm{Fel} / \mathrm{H}}}{\rightleftharpoons}\left[\mathrm{Fe}(\mathrm{Cb})_{2} \mathrm{H}^{5-}\right. \\
& \log \beta_{\mathrm{FeL}_{3} \mathrm{H}}=50.77 \\
& \mathrm{Fe}^{3+}+3 \mathrm{Cb}^{3-}+3 \mathrm{H}^{+} \stackrel{\beta_{\mathrm{red} 3 \mathrm{H}_{2}}}{\rightleftharpoons}\left[\mathrm{Fe}(\mathrm{Cb})_{3} \mathrm{H}_{2}\right]^{4-} \\
& \log \beta_{\mathrm{FeL}_{3} \mathrm{H}_{2}}=62.03 \\
& \mathrm{Fe}^{3+}+3 \mathrm{Cb}^{3-}+3 \mathrm{H}^{+} \stackrel{\beta_{\mathrm{rd} \mathrm{CH}_{3}}}{\rightleftharpoons}\left[\mathrm{Fe}(\mathrm{Cb})_{3} \mathrm{H}_{3}\right]^{3-} \\
& \log \beta_{\mathrm{FeL}_{3} \mathrm{H}_{3}}=72.13
\end{aligned}
$$

Thus, the real comparison with $\mathrm{Vb}$ or Cat should be done for the formation constant of the complex $\left[\mathrm{FeCb}_{3}\right]^{6-}$. Obviously, to obtain $\log \beta\left[\mathrm{FeCb}_{3}\right]^{6-}$ from $\log \beta_{\mathrm{FeL} 3 \mathrm{H}}=50.77$, the protonation constant of the complex is required. If it is assumed that this $\mathrm{pK}$ is approximately equal to that of the free ligand, i.e. $\mathrm{pK}=10.6$ for amine moiety of chrysobactin, then a result of: $\log \beta_{\mathrm{FeL} 3}=\log \beta_{\mathrm{FeL} 3 \mathrm{H}}-\mathrm{pK}=$ $50.8-10.6=40.2$. Of course, this is an approximation because the $\mathrm{pK}$ of the complexed ligand is not necessarily equal to that of the free ligand, a fact that can be evidenced in the difference between $\beta$ constants that are equal to $\mathrm{pK}$ of the complexed ligand, according to eqn (8) and (9).

$$
\begin{aligned}
& \log \beta_{\mathrm{FeL} 3 \mathrm{H} 3}-\log \beta_{\mathrm{FeL} 3 \mathrm{H} 2}=72.13-62.03=10.10 \\
& \log \beta_{\mathrm{FeL} 3 \mathrm{H} 2}-\log \beta_{\mathrm{FeL} 3 \mathrm{H}}=62.03-50.77=11.26
\end{aligned}
$$

With this assumption, the global complexation constant of $\mathrm{Cb}$ determined above as 40.2 compares quite well with the same global equilibrium constant determined for $\mathrm{Vb}$ as the sum of the stepwise formation constants of the complex, i.e., $\log \beta\left[\mathrm{FeVb}_{3}\right]^{3-}=\sum\left(\log K_{\mathrm{ML} n}\right)_{n=1,2,3}=42.7$, and also with that of catechol, i.e., $\log \beta\left[\mathrm{FeCat}_{3}\right]^{3-}=\sum\left(\log K_{\mathrm{ML} n}\right)_{n=1,2,3}=44.6$.

In the aim to found additional information of the complexation mode of $\mathrm{Vb}$, we have also studied the ferric complexation by 2,4-dihydroxy- $N$-(2-hydroxyethyl)benzamide (Dhb) andcatechol under the same experimental conditions of $\mathrm{Vb}$.

The ferric ions complexation by catechol is already referenced in the literature ${ }^{28,29}$ and our results were completely consisting with those published and listed in Table 1. Fig. S2† in the Supplementary information shows the ferric-catechol visible spectrum as a function of $\mathrm{pH}$. In concordance with $\mathrm{Vb}-$ ferric complex formation, at basic $\mathrm{pH}(>8)$, purple-red coloured solutions of $\mathrm{Cat}-\mathrm{Fe}^{3+}$ were observed and display a strong absorption band centered at $485 \mathrm{~nm}$; lowering the $\mathrm{pH}$ from 7.5 to 5.5 , approximately, the maximum wavelength absorption shifts progressively to longer wavelengths with maximum at $570 \mathrm{~nm}$. The quantitative treatment of the data, following the same procedure as for $\mathrm{Vb}$, affords the results of Table 1. 
The interest in the ligand Dhb was due to the absence of the catechol function; therefore, the molecular structure of this ligand (displayed in Scheme 2) does not make possible the ferric coordination through the catecholate function. Nevertheless, we also found ferric complexation: redpurple solutions were obtained at acidic $\mathrm{pH}$ values, in contrast to that observed with both $\mathrm{Vb}$ and catechol, whose red-purple complexes appear at basic $\mathrm{pH}$.

First of all, we analysed the acid-basic properties of free Dhb. Aqueous diluted solutions (0.17 $\mathrm{mM}$ ) of Dhb, in acidic medium absorbs below $330 \mathrm{~nm}$ showing two absorption bands with maxima at 254 and $292 \mathrm{~nm}$, respectively, and shift, respectively, to 278 and $313 \mathrm{~nm}$ in basic medium. The optical intensity of the largest wavelength absorption band increases strongly with the $\mathrm{pH}$ (Fig. S3†).

The potentiometric titration of free Dhb has been performed from solutions that contain $10^{-2} \mathrm{M}$ of ligand and titrating with a standardized sodium hydroxide solution in order to remove the two protons of the molecule and to obtain the $\mathrm{pK}_{1}$ and $\mathrm{pK}_{2}$ values that are listed in Table 1. The value of $\mathrm{pK}_{1}=7.55$ was ascribed to the dissociation of the proton from the $o$ hydroxylgroup of catechol moiety. This result is lower than those found for other phenols and relatively similar to that of $\mathrm{Vb}(\mathrm{pK}=6.79)$ and $\mathrm{Cb}(\mathrm{pK}=6.73)^{17}$ because of both the effect of the amidemoiety and the formation of intramolecular H-bonds, as it was discussed previously.
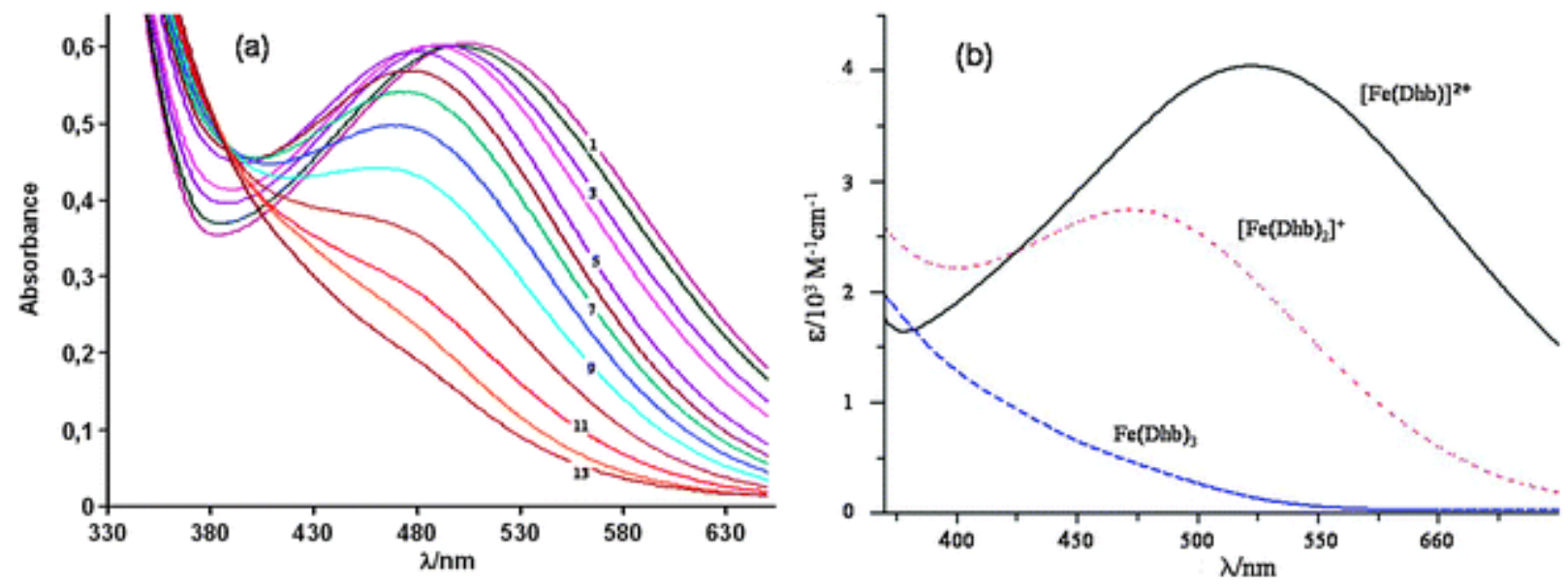

Fig. 4 (a) Visible spectra (corrected for dilution) of Dhb $(1.5 \mathrm{mM})-\mathrm{Fe}^{3+}(0.41 \mathrm{mM})$ complexes in 0.010 $\mathrm{M} \mathrm{NaCl}$ as a function of $\mathrm{pH}$; the $\mathrm{pH}$ values are: (1) 3.06 ; (2) 3.23 ; (3) 3.48; (4) 3.65; (5) 4.05; (6) 4.29; (7) 4.64; (8) 4.87; (9) 5.37; (10) 5.59; (11) 6.03; (12) 6.24; (13) 6.97; (b) Calculated electronic spectra of ferric-Dhb complexes.

The iron(III) complexation by Dhb was studied by UV-Vis spectrophotometry at [Dhb] $=1.5 \mathrm{mM}$ and $\left[\mathrm{Fe}^{3+}\right]=0.41 \mathrm{mM}$ in $0.01 \mathrm{M} \mathrm{NaCl}$ aqueous solutions. The spectrophotometric titration of complex formation was started with an acid solution of $\mathrm{pH}=3.06(\mathrm{HCl})$ and proceeding with addition of small aliquots (10 to $20 \mu \mathrm{L}$ ) of standardized $\mathrm{NaOH} 0.010 \mathrm{M}$. The resulting spectra are shown in Fig. 4(a). The red-purple solutions that absorb at $497 \mathrm{~nm}$ at low $\mathrm{pH}$ become pale yellow at biologic $\mathrm{pH} \sim 7$. At 
$\mathrm{pH}>4$ the wavelength maxima shifts progressively to blue and meanwhile the absorption intensity decreases.

The potentiometric titration was performed under similar experimental conditions. When the solution of $\mathrm{Fe}^{3+}$ was added to the Dhb solution, the complexation of iron is evidenced by the instantaneous appearance of red-purple colour together with the notable decrease of the $\mathrm{pH}$ because of the proton-loss of the $o$-hydroxyl group. The three successive complexation equilibria can be represented by eqn (10), where $n=1,2$, or 3 and $\mathrm{Dhb}^{-}$accounts for the Dhb with the $o$-hydroxyl ionized, i.e. the salicylate group coordinates the iron ion.

$$
\mathrm{Fe}^{3+}+n \mathrm{Dhb}^{-} \stackrel{K_{\mathrm{ML}_{n}}}{\rightleftharpoons}\left[\mathrm{Fe}(\mathrm{Dhb})_{n}\right]^{3-n}
$$

Both spectrophotometric and potentiometric titration data were fitted with Hyperquad suite to obtain the complex stability constants. In spite of the fact that at high $\mathrm{pH}$ the ferric-Dhb is a pale yellow colour, the best fitting process was obtaining also assuming the formation of tris(Dhb) complexes. Fig. 4(b) shows the calculated electronic spectra for ferric mono-, bis-, and tris(Dhb) complexes and it can be seen the presence of the later complex, although it is the minority species. The complex stability constants obtained in this manner are listed in Table 1and are in good agreement with those obtained with compounds that chelate iron(III) through salicylate function: $\log K_{\mathrm{ML} 1}=9.7$ for methyl salicylate and $\log K_{\mathrm{ML} 1}=10.0$ and $\log K_{\mathrm{ML} 2}=7.3$ for salicylamide (at ionic strength of 3 M). ${ }^{30}$ Obviously, the corresponding equilibrium constants are several orders of magnitude lower than those of the other compounds collected in Table 1, which bind to iron ions through the catecholate group.

In order to approach the molecular structure of the ferric-tris $(\mathrm{Vb})$ complex, theoretical calculations were performed. Interestingly, the results show that both intra- and inter-molecularhydrogen bonds were formed, respectively, between the H-atoms of guanidine group and the carboxyl or the carbonyl groups, see Fig. 5. Moreover, the electrostatic interactions that could take place between the charged parts of serine-carboxylate and arginine-guanidinium groups of two neighboring Vanchrobactins, yielded an organized system resembling the cyclic triester of enterobactin, the most effective iron chelator at physiological $\mathrm{pH}$ yet characterized. 


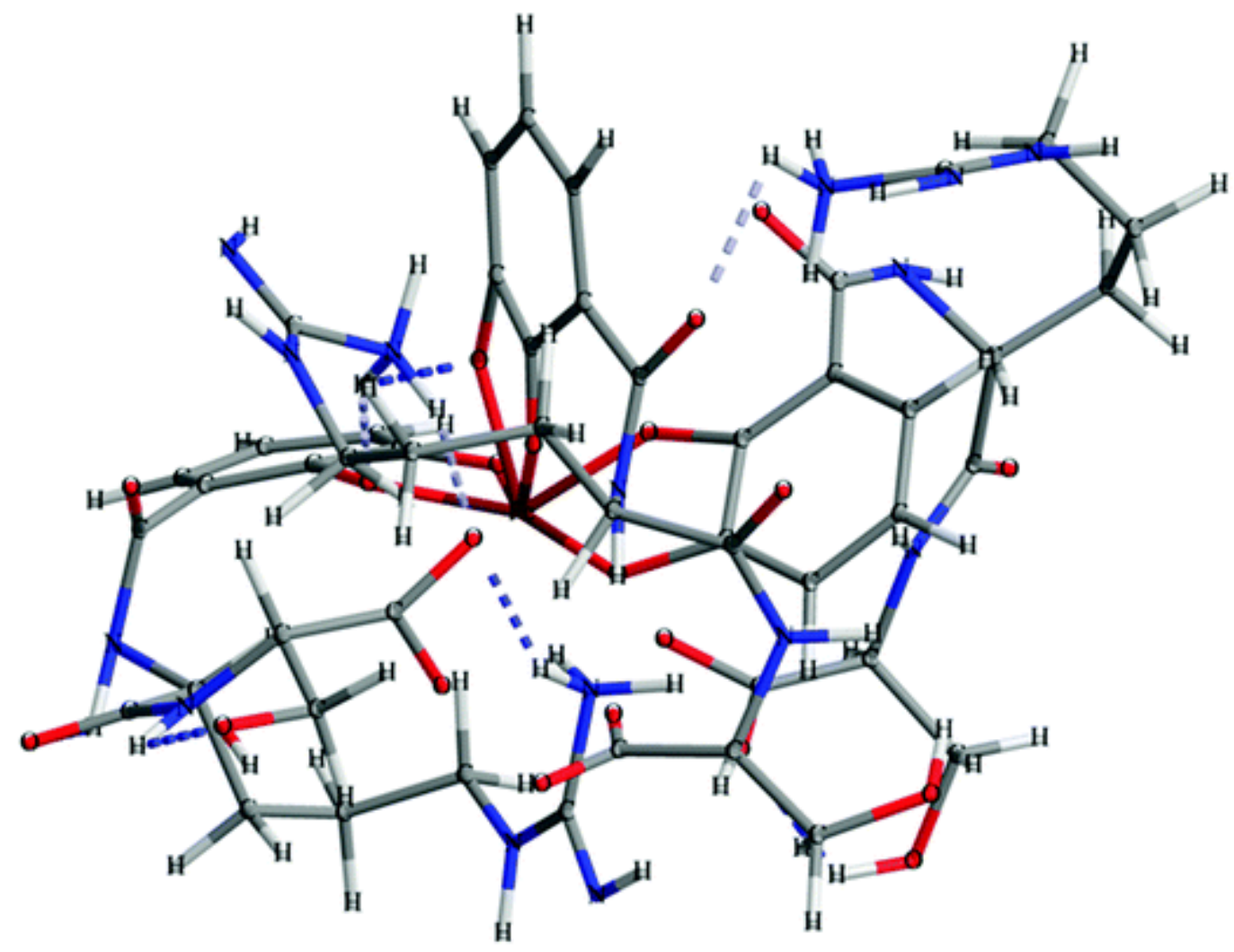

Fig. 5 Calculated structure of $\left[\mathrm{Fe}(\mathrm{Vb})_{3}\right]^{3-}$ (molecular modelling performed with the ChemBio3D Ultra 12.0 program at the MM2 level). The interstand and intrastrand hydrogenbonds are included as --- (distances ranging from 1.7 to $2.1 \AA$ ).

\section{Conclusions}

We have presented a physicochemical study of the binding properties of iron(III) by Vanchrobactin, a monocatecholate-type siderophore produced by the fish-pathogenic bacterium Vibrio angillarum serotype $\mathrm{O} 2$. We have determined the protonation constants of the free ligand, characterized the various ferric species of $\mathrm{Vb}$, and determined the corresponding stability constants. On the basis of these thermodynamic parameters, we were able to model the $\mathrm{Fe}^{3+}$ uptake by $\mathrm{Vb}$ under the physiological conditions of $\mathrm{pH}=7.4,\left[\mathrm{Fe}^{3+}\right]_{\mathrm{tot}}=10^{-6} \mathrm{M}$ and $[\mathrm{Vb}]_{\mathrm{tot}}=10^{-5} \mathrm{M}$ as $\mathrm{pFe}(\mathrm{Vb})=20$. We have also studied the iron complexation by catechol and Dhb, i.e. two ferric ligands that bear independently the potential coordination sites of $\mathrm{Vb}$. The results obtained with Cat are in perfect agreement with literature data. The most striking feature is that Dhb forms red-purple ferric complexes in acidic medium through the salicylate function showing high ability for iron uptake. The ferric-Dhb complex, $[\mathrm{Fe}(\mathrm{Dhb})]^{+2}$ is clearly the predominant species. The comparison of the results obtained with the three chelating agents of ferric ions shows the appearance of synergistic effects on $\mathrm{Vb}$, which contains the binding sites of both Dhb and Cat: $\mathrm{Vb}$ is the best chelating agent either in acid or basic media. Nevertheless, enterobactin is by far a stronger chelator than $\mathrm{Vb}$, as shown by the significantly different $\mathrm{pFe}$ values $(\mathrm{pFe}=35.6$ for ent $)$, but $\mathrm{Vb}$ is a better chelator than the rest of the ligands listed in Table 1, for which we calculate $\mathrm{pFe}$ values equal to: $17.3 ; 14.7 ; 14.7$, and 15.2 , respectively to $\mathrm{Cb}$, 
DMB, Dhb, and Cat. In summary, bacteria employing Vanchrobactin-mediatediron transport thus are able to compete effectively for iron both with other microorganisms and with the mammals within which they live.

\section{Acknowledgements}

Financial support from the Dirección General de Investigación, Ministerio de Educación y Ciencia, of Spain — cofunded by FEDER - (Projects CTQ2008-04429 and CTQ2005-00793), and Xunta de Galicia (Project 10PXIB103157PR) is gratefully acknowledged. R. G. S. thanks the Parga Pondal Programe.

\section{References}

1. A. L. Crumbliss and J. M. Harrington, Adv. Inorg. Chem., 2009, 61, 179

2. T. Franza, B. Mahé and D. Expert, Mol. Microbiol., 2005, 55, 261

3. J. P. Michael and G. Pattenden, Angew. Chem. Int. Ed., 1993, 32, 1

4. K. N. Raymond, G. Müller and B. F. Matzanke, Top. Curr. Chem., 1984, 123, 49

5. J. B. Neilands, J. Biol. Chem., 1995, 270, 26723 ; J. B. Neilands, Annu. Rev. Microbiol., 1982, 36, 285

6. C. Ratledge and L. G. Dover, Annu. Rev. Microbiol., 2000, 54, 881

7. H. R. Harris, C. J. Carrano, S. R. Cooper, S. R. Solen, A. Avdeef, J. V. McArdle and K. N. Raymond, J. Am. Chem. Soc., 1979, 101, 6097

8. Microbial Iron Metabolism, ed. J. B. Neilands, Academic Press, New York, 1974

9. I. G. D'Brien and F. Gibson, Biochim. Biophys. Acta, 1970, 215, 393

10. W. R. Harris and K. N. Raymond, J. Am. Chem. Soc., 1979, 101, 6534

11. W. R. Harris, K. N. Raymond and F. L. Weitl, J. Am. Chem. Soc., 1981, 103, 2667

12. A.-M. Albrecht-Gary, S. Blanc, N. Rochel, A. Z. Ocaktan and M. A. Abdallah, J. Inorg. Chem., 1994, 33, 639

13. S. Dhungana, R. Michalczyk, H. Boukhalfa, J. G. Lack, A. F. Koppisch, J. M. Fairlee, M. T. Johnson, C. E. Ruggiero, S. G. John, M. M. Cox, C. C. Browder, J. H. Forsythe, L. A. Vanderberg, M. P. Neu and L. E. Hersman, BioMetals, 2007, 20, 853

14. R. R. Chowdhury, A. K. Crane, C. Fowier, P. Kwong and C. M. Kozak, Chem. Commun., 2008, 94

15. M. Presmark, D. Expert and J. B. Neilands, J. Biol. Chem., 1989, 264, 3187

16. M. Persmark and J. B. Neilands, BioMetals, 1992, 5, 29 
17. V. Tomisic, S. Blanc, M. Elhabiri, D. Expert and A.-M. Albrecht-Gary, Inorg. Chem., 2008, 47, 9419

18. (a) R. G. Soengas, C. Anta, A. Espada, V. Paz, I. R. Ares, M. Balado, J. Rodríguez, M. L. Lemos and C. Jiménez, Tetrahedron Lett., 2006, 47, 7113 ; (b) R. G. Soengas, C. Anta, A. Espada, R. M. Nieto, M. Larrosa, J. Rodríguez and C. Jiménez, Tetrahedron Lett., 2007, 48, 3021

19. R. G. Soengas, M. Larrosa, M. Balado, J. Rodríguez, M. L. Lemos and C. Jiménez, Org. Biomol. Chem., 2008, 6, 1278 .

20. (a) R. C. Hider, A. R. Mohd-Nor, J. Silver, I. E. G. Morrison and L. V. C. Rees, J. Chem. Soc., Dalton Trans., 1981, 609 ; (b) R. C. Hider, B. Howlin, J. R. Miller, A. R. Mohd-Nor and J. Silver, Inorg. Chim. Acta, 1983, 80, 51

21. A. A. Avdeef, S. R. Sofen, T. L. Bregante and K. N. Raymond, J. Am. Chem. Soc., 1978, 100, 5362

22. I. Brandariz, J. L. Barriada, T. Vilarino and M. E. Sastre de Vicente, Monatsh. Chem., 2004, 135, 1475

23. P. Gans, A. Sabatini and A. Vacca, Talanta, 1996, 43, 1739

24. C. F. Baes, J. R. and R. E. Mesmer, The hydrolysis of Cations, John Wiley and Sons, NY, 1976, pp. 235

25. R. Stewart, The proton: Applications to Organic Chemistry, Academic Press, London, 1985

26. E. Iglesias, J. Phys. Chem., 1996, 100, 12592 ; E. Iglesias, J. Org. Chem., 2003, 68, 2680

27. D. D. Perrin, B. Dempsey and E. P. Serjeant, $p K_{a}$ Prediction for Organic Acids and Bases, Chapman\&Hall, London, 1981

28. H. Kipton, J. Powell and M. C. Taylor, Aust. J. Chem., 1982, 35, 739

29. R. J. Motekaitis and A. E. Martell, Inorg. Chim. Acta, 1991, 183, 71

30. A. E. Martell, R. M. Smith and R. J. Motekaitis, Critically Selected Stability Constants of Metal Complexes, Texas A\&M University, 2004. Database Version 8.0 